\title{
Transference focused psychotherapy: Overview and update
}

\author{
Otto F. Kernberg*, Frank E. Yeomans**, John F. Clarkin ${ }^{\star * *}$ and \\ Kenneth N. Levy**** \\ New York Presbyterian Hospital, 21 Bloomingdale Road, White Plains, New York 10605, \\ USA - okernber@med.cornell.edu
}

(Final version accepted 4 February 2008)

\begin{abstract}
This paper describes a specific psychoanalytic psychotherapy for patients with severe personality disorders, its technical approach and specific research projects establishing empirical evidence supporting its efficacy. This treatment derives from the findings of the Menninger Foundation Psychotherapy Research project, and applies a model of contemporary psychoanalytic object relations theory as its theoretical foundation. The paper differentiates this treatment from alternative psychoanalytic approaches, including other types of psychoanalytic psychotherapy as well as standard psychoanalysis, and from three alternative non-analytical treatments prevalent in the treatment of borderline patients, namely, dialectic behavior therapy, supportive psychotherapy based on psychoanalytic theory, and schema focused therapy. It concludes with indications and contraindications to this particular therapeutic approach derived from the clinical experience that evolved in the course of the sequence of research projects leading to the empirical establishment of its efficacy.
\end{abstract}

Keywords: borderline personality disorder, comparative analysis of psychotherapeutic treatments, interpretation, object relations theory, psychoanalytic psychotherapies, randomized controlled trials, splitting mechanisms, technical neutrality, transference analysis

\section{Introduction}

Transference Focused Psychotherapy (TFP) evolved out of the Menninger Foundation's Psychotherapy Research Project, particularly its quantitative studies, that found that patients with severe personality disorders or borderline personality organization - which would then refer to patients presenting significant ego-weakness improved more with a psychotherapeutic approach that focused on transference

\footnotetext{
*Professor of Psychiatry, Weill Medical College of Cornell University, Director, Personality Disorders Institute, The New York Presbyterian Hospital, Payne Whitney Westchester, Training and Supervising Analyst, Columbia University Center for Psychoanalytic Training and Research.

**Clinical Associate Professor of Psychiatry, Weill Medical College of Cornell University Director of Training, Personality Disorders Institute, The New York Presbyterian Hospital, Payne Whitney Westchester, Director, Personality Studies Institute, New York, New York.

***Clinical Professor of Psychology in Psychiatry, Weill Medical College of Cornell University, Co-Director, Personality Disorders Institute, The New York Presbyterian Hospital, Payne Whitney Westchester.

****Assistant Professor, Department of Psychology, Pennsylvania State University.

The research presented in this article was supported by grants from the National Institute of Mental Health (MH53705, John F. Clarkin, PI; MH12530, Kenneth N. Levy, PI), International Psychoanalytic Association (Kenneth N. Levy, PI), the Köhler Foundation of Munich, a grant from the Borderline Personality Disorder Research Foundation (BPDRF; Otto F. Kernberg and John F. Clarkin, Co-PIs), and the DeWitt Wallace Reader's Digest Fund. We thank the BPDRF founder and executive officer, Marco Stoffel, and the scientific board for their advice and encouragement. We gratefully acknowledge the assistance of our colleagues in the Institute for Personality Disorders at Weill Cornell Medical College.
} 
interpretations in the sessions, while providing the patient with as much support outside the sessions as was necessary to maintain the treatment frame, than similar patients treated by either standard psychoanalysis or supportive psychotherapy (Kernberg et al., 1972). Beginning in 1976, a group of psychoanalysts and researchers developed this approach more systematically, culminating in the work of the Personality Disorders Institute at the Westchester Division of the New York Presbyterian Hospital over the past 10 years. We developed a theoretical model, a corresponding theory of technique, and clinical approaches in the treatment of severe personality disorders, testing various psychoanalytic hypotheses in terms of interpretive approaches to patients, and evaluating the therapeutic interactions by systematic videotaping of long-term treatments. In exploring the Menninger findings from the perspective of contemporary developments in psychoanalytic theory, particularly an object relations theory perspective, we operationalized the definitions and sharpened the application of psychoanalytic techniques to borderline patients, particularly regarding interpretation, transference analysis, technical neutrality and countertransference utilization. We differentiated more sharply the supportive effects of many interventions from supportive techniques proper, and applied a purely analytic model to transference interpretation. We developed techniques to maintain the treatment frame under even severe acting-out conditions, and specified initial treatment contracts with extremely regressive borderline patients. We evolved a differentiation of overall, long-range treatment objectives and corresponding 'treatment strategies,' the systematization of interventions that maintain in each session the conditions necessary for working with this patient population or 'treatment tactics', while attempting to define the specific instruments of psychoanalytic treatment throughout its course, or 'treatment techniques'. In what follows, we shall outline these treatment strategies, tactics and techniques.

\section{Strategies}

Our assumption was that patients with severe personality disorders or borderline personality organization suffer from the syndrome of identity diffusion, that is, a chronic, stable lack of integration of the concept of self and of the concept of significant others, and that the ultimate cause of that syndrome was the failure of psychological integration resulting from the predominance of aggressive internalized object relations over idealized ones. In an effort to protect the idealized segment of the self and object representations, these patients' ego was fixated at a level of primitive dissociative or splitting mechanisms and their reinforcement by a variety of other primitive defensive operations predating the dominance of repression, namely, projective identification, omnipotence and omnipotent control, devaluation, denial, and primitive idealization. Identity diffusion is reflected clinically in the incapacity to accurately assess self and others in depth, to commit in depth to work or a profession, to establish and maintain stable intimate relationships, and in a lack of the normal subtlety of understanding and tact in interpersonal situations. Primitive defensive operations, which correspond to patients' split psychological structure and identity diffusion, are manifest in patients' behavior and are an important feature of their maladaptive dealing with negative affect and conflictual interpersonal situations, contributing fundamentally to chaos and breakdown in intimacy, in work, in creativity, and in social life. In an earlier paper, one of us 
(Kernberg, 2006) has described in detail the etiology, psychopathology, empirical research and clinical assessment of the syndrome of identity diffusion.

The main strategy in the transference focused psychotherapy (TFP) of borderline personality organization consists in the facilitation of the (re)activation in the treatment of the patient's split-off internalized object relations that are then observed and interpreted in the transference. The conditions of treatment established by the treatment contract facilitate this reactivation of internalized object relations in the here and now. TFP is carried out in face-to-face sessions, a minimum of two and usually not more than three sessions a week. The patient is instructed to carry out free association, usually starting around the problems that brought him to treatment, and the therapist restricts his role to careful observation of the activation of regressive, split-off relations in the transference, helping to identify them and interpret their segregation in the light of these patients' enormous difficulty in reflecting on their own behavior and interactions.

The concept of identity diffusion is based on the idea of a psychological structure composed of multiple split-off object relations, positive and negative, each of them reflecting a dyadic unit of a self-representation, an object-representation and a dominant affect linking them. These dyadic units, or dyads, originate in the internalization, and subsequent unconscious revision, of affectively intense experiences in the course of early development. The vicissitudes of development in borderline individuals keep these primitive object relations dyads from becoming integrated into more nuanced and realistic representations of self and other. It is assumed that, in the borderline individual's experience, the activation of one or more of these split-off dyads determine the patient's perception of himself and the other, viz. the therapist. It is assumed that an individual internalizes both poles of a relation - the role of self and that of the 'other' - and that the patient identifies variously with the 'self' representation and the 'other' representation (both having become transitorily self-representations, although experienced alternately and with varying degrees of awareness). The reactivation of a dyad occurs with rapid role reversals in the transference, so that the patient may identify with a primitive self-representation while projecting a corresponding object representation onto the therapist, while, minutes later, the patient identifies with the object representation while projecting the self-representation onto the therapist. The difference between the two poles of the dyad does not constitute the fundamental split in the patient's internal world. The dyad is the internalization of a relationship with complementary roles. The internal split is between dyads imbued with solely positive, idealizing affects and dyads imbued with negative, aggressive affects that must be kept separate to avoid intense anxiety. Interpretations first direct the patient's attention to his identification with both roles of a given dyad and then to the co-existence within him of segregated dyads with opposing affective charges. Engaging the patient's observing ego paves the way for interpreting the conflicts that keep these dyads, and corresponding views of self and other, separate and exaggerated. Until these representations are integrated into more nuanced and modulated ones, the patient will continue to perceive himself and others in exaggerated, distorted and rapidly shifting terms.

For example, the patient may act as a desperate, powerless child who is trying to gain the attention of an indifferent mother, projecting the image of the indifferent and potentially dangerous mother onto the therapist, while, 10 minutes later, it is the patient whose behavior is that of an indifferent, rejecting mother while the ther- 
apist, under the effect of projective identification, experiences himself as an impotent child that is trying to obtain the attention of the aloof mother. Whether the patient is in the 'child' or the 'mother' role, this dyad sustains a negative emotional charge and must be distinguished from split-off dyads carrying positive, idealizing emotional charges that will appear at other times. Interpretation ultimately consists in linking the dissociated positive and negative dyads/transferences, leading to an integration of the mutually split-off idealized and persecutory segments of experience, helping the patient achieve a coherent and nuanced sense of self and others, thus resolving identity diffusion. In the present example, the aloof mother/impotent child dyad is a persecutory part-object relation. Its opposite may be an idealized, a loving mother/happily dependent child relationship that, in turn, is expressed in an oscillating fashion. The interpretation of these split-off relationships occurs in a characteristic sequence of three steps. Step one is the formulation of the total relationship that seems to be activated at that moment, using metaphorical statements to present the situation as completely as possible in a way that can be understood by the patient, and the clarification of who enacts what role in that interaction. The therapist's comments are based on his observations, his countertransference utilization, and on clarifications that have been sought of the patient's experience of the relationship at each moment.

Step two consists in the observation of the interchange of the corresponding roles between patient and therapist, an important step that permits the patient, throughout time, to understand his unconscious identification with the object representation - that is usually expressed in behaviors without full awareness - as well as the selfrepresentation, leading to a gradual awareness of the mutual complementarity of these two roles. Step two is carried out by the clarification and confrontation of both the oscillating poles of a given dyad. However, since the idealized and persecutory relationships that are activated remain typically split-off from each other in different dyads, the patient may become able to recognize his identification with both poles of a negative, or a positive, dyad while still maintaining the split or dissociated nature that separates all good from all bad relationships. Thus, for example, the indifferent mother/desperate child dyad may trade places with the totally caring mother/ happily dependent child relation that, in turn, involves alternative reciprocal role identifications. Therefore, the patient's confusion is not simply in the oscillation within a dyad, but also in the fact that a dyad carrying a libidinal affect may be activated at one moment, while a dyad carrying an aggressive affect may be activated at another. Understanding the motivation for keeping these dyads separate is one of the main objectives of the interpretive work, the focus of the next step.

Step three consists in this interpretive linking of the mutually dissociated positive and negative transferences, the transferences reflecting the idealized and persecutory relationships, leading to an integration of the mutually split-off idealized and persecutory segments of experience, the corresponding resolution of identity diffusion, and the modulation of intense affect dispositions as primitive euphoric or hypomanic affects are integrated with their corresponding fearful, persecutory, aggressive opposites. For example, in the transference developments described before, the therapist may interpret the need for an idealized relationship as a defense against the emergence of the persecutory one at the point of any frustration, leading to the patient's recognition that the therapist is really neither as terrible nor as ideal as experienced before by the patient; and the patient is neither as ragefully needy and 
frustrated nor as (temporarily) totally satisfied and fulfilled as experienced before. This third step brings about a significant integration of the patient's ego identity, as an integrated view of self - more complex, rich and nuanced than the simplistic and extreme split-off representations - and a corresponding integrated view of significant others replace their split-off previous nature. This is also reflected in an experience of appropriate depressive affects, reflecting the capacity for acknowledging one's own aggression that had previously been projected or experienced as dysphoric affect, with concern, guilt, and the wish to repair good relationships damaged in fantasy or reality, becoming dominant.

An example is that of a woman who started TFP at age 35 with depression, chronic suicidal ideation, and an inability to maintain social relations or any job because of chronic arguments with others. After initial evaluation determined a diagnosis of borderline personality disorder with narcissistic features, the therapist proposed a treatment contract delineating the patient's and therapist's responsibilities and roles in the therapy. In addition to the patient's responsibilities regarding attendance, participation (modified free association), and payments, the patient's role would be to call 911 or go to the emergency room if at risk of acting selfdestructively (thus eliminating the secondary gain of increased contact with the therapist). As the therapy began, the first prominent dyad that emerged in her discourse was the image of a weak, injured self who was constantly berated and put down by others. Yet, the patient's initial interactions with the therapist were characterized by a non-stop discourse on her part that left the therapist feeling controlled and unable to speak freely. Exploration of this revealed a devalued image of self in relation to another who would inevitably criticize and abandon her in the context of an interaction where the patient was controlling the therapist.

There are three important points: (1) the patient's controlling behavior was such that no one other than a therapist dedicated to helping her would stay in a relation with her (an example of how the internal representations of borderline patients generate behavior that brings about the outcome they fear); (2) the patient's primitive defense mechanisms were apparent: her projection of the 'bad' abandoning object on the therapist with the need to then control it in him; and (3) the patient's controlling actions and the therapist's countertransference (feeling controlled) were the most affectively-laden part of the sessions and therefore needed to be addressed first. The therapist first interpreted the patient's omnipotent control in a way that freed the patient to participate in a more open and interactive interchange.

Responding to the patient's rapid-fire speech in every session, the therapist commented: "Have you noticed how you fill the sessions with a kind of pressured speech that does not leave me any room to comment? [Generally, if the therapist tried to speak, the patient would speak over him.] It is as though you feel the need to control me, to keep me from acting freely."

Patient: "If I didn't control you, you'd leave me, like everyone else."

Exploration of this fear helped the patient understand that her behavior was rooted in an anxiety stemming from an internal image of the other that determined how she experienced her therapist. The next stage of therapy was marked by the patient's increasing berating of the therapist, which she did not recognize as such consciously. She felt she was reacting in a justified way to his shortcomings and failures toward her (e.g. his going away at times). The therapist helped the patient to observe her own identification with and enacting of the devaluing, critical one, to see 
its relation to feeling devalued and criticized, and also to understand that neither one of these needed to be the case. The patient gained awareness that the drama she experienced endlessly with others was the enactment of a relationship between two parts of herself and that she was living the contradiction of being both the victim and the critic/attacker, although with less awareness of the latter and usually experiencing this relationship as between her and others (a situation she often created) rather than within herself. This awareness allowed her to begin to assume responsibility for and tame the harsh critical part within her. In terms of the transference meanings of the reactivated internalized object relations from her unconscious past, the grandiose, controlling, derogatory object represented an aspect of her grandiose self identified with the image of a dominant, persecutory mother, in relation to whom she experienced herself as an impotent, depreciated, attacked little girl.

As therapy advanced, there were signs of the patient's attachment to the therapist: coming on time while protesting that therapy was a waste of time, missing her therapy while angrily proclaiming that her therapist was irresponsible for going away, etc. Her therapist made the interpretation that it must be difficult for her to be attached to him (thus going a step beyond anything she had stated and bringing the positive dyad into their dialogue more explicitly) because of her fear that the kind of longing she experienced for him could never be reciprocated by anyone. The therapist's matter-of-fact mention of this imagined positive relationship freed the patient to begin to discuss her fantasies of an ideal relationship with him as the perfect provider and protector she had never experienced. The patient had been reluctant to express this idealized view of their relation for fear that the negative, rejecting image of the other would prove real and destroy her longing for closeness in a brutally humiliating way. The ability to discuss and observe both sides of the split allowed the patient to achieve an integrated, more balanced view of herself, others, and relationships.

Another example, from the advanced phase of the treatment is that of a 26 yearold borderline patient who had sharply alternative experiences of the therapist: on the one hand, he was a stern, scolding father who harshly tried to make her 'behave', very critical of her sexual life and totally insensitive to her moods and feelings; at other times, he seemed to be a sexually tolerant, even warm, well-intentioned but weak man whom she could seduce into being manipulated by the display of her sexual attractiveness. But now he could not be trusted and provided excitement but no real understanding. This pseudo-idealization of a weak and gullible man who provided her with a sense of power and security in her sexual attractiveness was the opposite of the feared, prohibitive and resented father, who, however, represented integrity and strength. At a certain point, the therapist was able to point out to her how this split in the image of her father, repeated in her failing relationships with men, represented a defense against the image of a powerful and sexually attractive father with whom a good relationship was forbidden because of unconscious oedipal guilt. This example, we may add, also illustrates how the predominance of primitive defensive operations does not preclude the availability of other, more advanced defenses and conflicts, particularly of an advanced oedipal kind, that are buried underneath the dominance of splitting and related mechanisms and the primitive condensation of oedipal and pre-oedipal issues that are characteristic for patients with severe personality disorders.

The intolerance of overwhelming emotional experiences is expressed in the tendency to replace such emotional experiences by acting out, in the case of most 
borderline patients, and somatization (Green, 1993). The fact that primitive conflicts manifest themselves in dissociated behavior rather than in the content of free association is a fundamental feature of these cases that facilitates transference analysis with a relatively low frequency of sessions, while the very intensity of those conflicts facilitates the full analysis of these transference developments. What is important in these cases is establishing very clear boundaries and conditions of the treatment situation, so that a 'normal' relationship is defined in the therapy that immediately enters into contrast with the distortions in the therapeutic relationship derived from the activation of primitive transferences. This leads to the discussion of a second major aspect of the treatment: the tactics used by the therapist in each session that create the conditions necessary for the use of interpretation and other treatment techniques.

\section{Tactics}

In the establishment of the treatment contract, in addition to the usual arrangements for psychoanalytic treatment, the therapist describes a structure to address urgent difficulties in the borderline patient's life that may threaten the patient's physical integrity or survival, that of other people, or the continuation of the treatment. This is done by setting up conditions under which the treatment can be carried out that involve certain responsibilities for the patient and certain responsibilities for the therapist. A typical example is that of patients with chronic characterological suicidal behavior, where the contract offered to the patient leaves the patient with the responsibility of either getting himself/herself to an emergency room when suicidal impulses become so strong that they cannot be controlled, or, if the patient can control them, a commitment to bring them up for exploration in the next session. It is important to underline that this applies to suicidal behavior that is characterological, a 'way of life', and not a symptom of severe depression. What is important in these structuring arrangements at the beginning of the treatment is, first, that the therapeutic structure eliminate the secondary gain of treatment, and, second, that, in a situation where limits or restrictions need to be established in order to preserve the patient's life or the treatment, the transference implications of these restrictions or limit-settings need to be interpreted immediately. The combination of limit-setting and interpretation of the corresponding transference development is an essential, highly effective, and, at times, life-saving tactic of the treatment. Yeomans et al. (1992) have described in detail the techniques and vicissitudes of contract setting, although TFP has evolved to include more flexibility in the use of the contract than is described in that text.

The manual of Transference Focused Psychotherapy (Clarkin et al., 2006) describes in detail the priorities to address in carrying out the therapy. With regard to choosing which theme to address at any given moment in the material that the patient brings to the session, the most important tactic is the general analytic rule that interpretation has to be carried out where the affect is most intense: affect dominance determines the focus of the interpretation. The most intense affect may be expressed in the patient's subjective experience, in the patient's nonverbal behavior, or, at times, in the countertransference - in the face of what on the surface seems a completely frozen or affectless situation (Kernberg, 2004). The simultaneous attention, by the therapist, to the patient's verbal communication, non-verbal behavior, and the countertransfer- 
ence permits diagnosing what the dominant affect is at the moment - and the corresponding object relation activated in the treatment situation. Every affect is considered to be the manifestation of an underlying object relation.

The second most important consideration in determining the selection of what is interpreted is the nature of the transference. This is easy to determine when major affect development coincides with transference development, but there are times where most affect occurs related to extra-transferential conditions or the patient's external world. Such affective dominance in the patient's external world, of course, always has transference implications as well; the focus, however, has to start on the external affectively invested situation, only shifting into a transference interpretation when the corresponding transference development clearly occupies the center of the patient's present interaction with the analyst. This is an important tactic derived from Fenichel's (1941) technical recommendations, and reflects a flexibility in this approach, that focuses simultaneously on the transference and on developments in these patients' external lives.

When treating patients with severe personality disorders, another tactical approach relates to certain general priorities that need to be taken up immediately, whether or not they reflect affective dominance in the session, although they usually do. These priorities include, in order of importance: (a) suicidal or homicidal behavior, (b) threats to the disruption of the treatment, (c) severe acting out in the session or outside, that threatens the patient's life or the treatment, (d) dishonesty, (e) trivialization of the content of the hour and (f) pervasive narcissistic resistances, that must be resolved by consistent analysis of the transference implications of the pathological grandiose self (Clarkin et al., 2006; Kernberg, 1984). Important tactical aspects of the treatment involve dealing with conditions of severe regression, including affect storms, micropsychotic episodes, deceptiveness, negative therapeutic reactions, and 'incompatible realities'. We have developed specific technical approaches to these situations, described in our manual.

\section{Techniques}

While 'strategies' refer to overall, long-range goals and their implementation in transference analysis, and 'tactics' to particular interventions in concrete hours of treatment, 'techniques' refers to the general, consistent application of technical instruments derived from psychoanalytic technique. The main technical instruments of Transference Focused Psychotherapy (TFP) are those referred to by Gill (1954) as the essential techniques of psychoanalysis, namely, interpretation, transference analysis, and technical neutrality. If psychoanalysis consists in the facilitation of a regressive transference neurosis and the resolution of this transference neurosis by interpretation alone carried out by the psychoanalyst from a position of technical neutrality, TFP may be defined, in terms of its technical utilization, by these same three instruments, somewhat modified, however, as we shall mention below, with the important contribution of countertransference analysis as an additional major technical instrument.

The use of interpretation focuses particularly on the early phases of the interpretive process, namely, clarification of the subjective experience of the patient (clarification of what is in the patient's mind rather than clarifying information to him), and confrontation, in the sense of a tactful drawing of attention to any incon- 
sistencies or contradictions in the patient's communication - either between what the patient says at one point in contrast to another, between verbal and nonverbal communication, or between the patient's communication and what is evoked in the countertransference. Nonverbal aspects of behavior become extremely important in the psychoanalytic psychotherapy of severe personality disorders. Interpretation per se, that is, the establishment of hypotheses regarding the unconscious functions of what has been brought forth by clarification and confrontation follows these two techniques. Interpretation as a hypothesis about unconscious meaning refers, first of all, to interpretation of unconscious meaning in the 'here and now', the 'present unconscious' (Sandler and Sandler, 1987), in contrast to genetic interpretations that link the unconscious meaning in the 'here and now' with assumed unconscious meanings in the 'there and then', that become important only in advanced stages of the treatment of severe personality disorders. Interpretation, in short, is applied systematically, but with heavy emphasis on its preliminary phases: clarification and confrontation, and the interpretation of the 'present unconscious'.

Transference analysis differs from the analysis of the transference in standard psychoanalysis in that, as mentioned before, it is always closely linked with the analysis of the patient's problems in external reality, in order to avoid the dissociation of the psychotherapy sessions from the patient's external life. Transference analysis also includes an implied concern for the long-range treatment goals that, characteristically, are not focused upon in standard psychoanalysis, except if they emerge in the transference. In TFP, an ongoing concern regarding dominant problems in the patient's life is reflected in the occasional introduction of reference to major conflicts that brought the patient into treatment or that have been discovered in the course of the treatment, bringing such conflicts into the treatment situation even if they are not transference-dominant at that point. This introduction of 'extra transference material' follows the therapist's assessment that a significant splitting operation is in process, shielding a certain important conflict in the patient's external life from exploration in the treatment. Here the therapist's overview of the total treatment situation and the total life situation of the patient may determine that he introduce a subject matter 'arbitrarily' (at times, at least in the patient's mind), and then focus on the transference development that occurs as a consequence of introducing such a major life theme. While transference analysis starts from session one, and in this regard the treatment has significant similarities with Kleinian technique (both because of the dominant emphasis on transference analysis and on primitive defenses and object relations), this bringing in of external reality is a fundamental difference from Kleinian and, to some extent, also from ego psychological psychoanalysis.

Technical neutrality is an ideal point of departure within the treatment at large and within each session because it counters patients' tendency to externalize their intrapsychic conflicts. However, at times it needs to be disrupted because of the urgent requirement for limit-setting and even in connection with the introduction of a major life problem of the patient that, at such point, would seem a non-neutral intervention of the therapist. Such deviation from technical neutrality may be indispensable in order to protect the boundaries of the treatment situation, and the patient from severe suicidal and other self-destructive behavior, and requires a particular approach in order to restore technical neutrality once it has been abandoned. What we do, following an intervention that clearly signifies a temporary deviation from technical neutrality (for example, by taking measures to control a 
patient's accumulation of medication with suicidal intentions), is the analysis of the transferential consequences of our intervention, to a point where these transferential developments can be resolved and then be followed with the analysis of the transference implications of the reasons that forced the therapist to move away from technical neutrality. Technical neutrality, in short, fluctuates throughout the treatment, but is constantly worked on and reinstated as a major process goal.

The utilization of countertransference as a major therapeutic tool has already been referred to as an important source of information about affectively dominant issues in the hour. The intensity of the countertransferences evoked by patients with severe character pathology and consequent severely regressive behavior and acting out in the transference requires an ongoing alertness to countertransference developments that the therapist has to tolerate in himself/herself, even under conditions of significant regression in countertransference fantasies and impulses of an aggressive, dependent, or sexual kind. That internal tolerance of countertransference permits its analysis in terms of the nature of the self-representation or the object representation that is being projected onto the therapist at that point, facilitating full interpretation of the dyadic relationship in the transference, so that countertransference is utilized in the therapist's mind for transference clarification. Countertransference should not be communicated directly to the patient but worked into transference interpretations. In this regard TFP follows strictly analytic criteria typical of the ego psychological, Kleinian, British Independent, and French approaches.

As Green (2000) has pointed out, the avoidance of traumatogenic associations drives borderline patients to jump from one subject to the next, thus expressing their 'central phobic position', and may seem bewildering to an analyst used to expecting the gradual development of a specific theme in free association, thus leading to clarify the subject matter that is being explored. Here, waiting for such a gradual deepening of free association is useless, because of this defensive jump from one subject to the next, also related to the splitting operations that affect the very language of the patient (Bion, 1968).

The corresponding technical approach in TFP consists of an effort to interpret rapidly the implication of each of the fragments that emerge in the hours, with the intention of establishing continuity by the very nature of the interpretive interventions that gradually establish a continuity of their own. This approach may be compared to the interpretive work with dreams, where the interpretation of apparently isolated fragments of the manifest dream content leads gradually to the latent dream content that establishes the continuity between the apparently disparate elements of the manifest content.

\section{Empirical findings}

Our research efforts from the beginning have been theory driven, interdisciplinary, and focused on an articulated model of treatment development (Kazdin, 2004) involving an extensive examination of the patient pathology, treatment articulation, and tests of both the effects of the treatment (e.g. symptom change) and how the treatment achieves its overall goal (e.g. mechanisms of change).

An object relations model of the borderline pathology led us to focus upon psychological manifestations of identity diffusion and inadequate/distorted conceptions of self and others. We have developed a self-report measure of personality organization, 
with attention to constructs of identity diffusion, primitive defenses, and reality testing (Lenzenweger et al., 2001). We have also utilized the Adult Attachment Interview (AAI) to examine the patients' articulated conceptions of self and others (Levy et al., 2006). This instrument yields not only a classification of attachment organization based upon present conceptions of self and others, but also produces a dimensional score of reflective functioning which can be used as a marker of change in treatment.

Our interdisciplinary approach has allowed us to examine the relationship between psychological or personality organization, and organization at the neurocognitive level of the organism. With Michael Posner, we examined the non-affective attention system in borderline patients compared to normals, and found that borderline patients are defective in conflict resolution (Posner et al., 2003). In extensive laboratory tests of neurocognitive functioning, we have demonstrated that borderline patients are deficient in executive functioning (Lenzenweger et al., 2004). In a further step to examine neurocognition that is affectively charged, we worked with David Silbersweig to utilize an emotional go/no go task in the fMRI environment to assess the process of affect regulation in borderline patients as compared to normals (Silbersweig et al., 2007). As hypothesized, BPD patients as compared to normals demonstrated decreased ventromedial prefrontal activity under conditions associated with the interaction of behavioral inhibition and negative emotion. In addition, under conditions of behavioral inhibition in the context of negative emotion, decreasing ventromedial prefrontal and increasing extended amygdalar-ventral striatal activities correlated highly with measures of decreased constraint and increased negative emotion in borderline patients.

The object relations model enhanced by these data provided a platform on which we could develop a treatment. Senior clinicians led by Otto Kernberg treated borderline patients while videotaping the process. Small clinical groups reviewed the treatments, session by session, and articulated the principles of the intervention. The resulting treatment manual (Clarkin et al., 2006) is an articulation of the principles of treatment as the treatment unfolds from early phase, to mid phase, to end phases, illustrated by clinical situations we have encountered.

With therapists trained in the treatment and a written description of the treatment, we were in a position to assess the effectiveness of the intervention. Our first study applied TFP to a sample of female borderline patients, and we compared the patients' clinical condition at the end of a year of treatment to their clinical condition during the year prior to the treatment. These preliminary results were encouraging as the patients treated with TFP showed a significant reduction in the number of patients who made suicide attempts, a significant decrease in the average medical risk of parasuicidal acts and improvement in the average physical condition following these acts, and also significantly fewer emergency room visits, hospitalizations and days hospitalized. After the year of TFP, 52.9\% of the subjects no longer met criteria for BPD (Clarkin et al., 2001).

The next step in treatment development was a randomized clinical trial in which TFP could be compared in its effectiveness with competing treatments. With the generous assistance of a grant from the Borderline Personality Disorder Research Foundation, we organized a randomized clinical trial to compare TFP with the existing empirically supported cognitive-behavioral treatment, DBT, and a supportive treatment that was psychodynamically oriented but did not use transference interpretations (Clarkin et al., 2004; Rockland, 1992). This design was unique in 
several respects. We included both female and male borderlines, whereas previous studies had included only females. The design had elements of effectiveness and efficacy studies, in that the assessment was done in a standardized way at the hospital, but treatment was provided by clinicians operating in the community.

We utilized individual growth curve analysis to investigate change in the six domains of outcome (suicidality, aggression, impulsivity, anxiety, depression, and social adjustment) over the one year of treatment. We first examined the impact of the three treatments on the rate of clinical change. The prediction of change toward improvement for each of the three treatments was significant for depression, anxiety, global functioning, and social adjustment (all $\mathrm{p}<.05$, effect sizes all in the large range $[\mathrm{r}>.36])$. TFP and DBT were significantly associated with improvement in suicidality $(\mathrm{p}<.01$, effect sizes $\mathrm{r}=.33$ and .34 , respectively), and TFP $(\mathrm{p}<.001$, effect size $\mathrm{r}=.44)$ and SPT $(\mathrm{p}<.05$, effect size $\mathrm{r}=.28)$ were significantly associated with improvement in anger. TFP was predictive of change in Barratt Factor 2 (attention impulsivity), irritability $(\mathrm{p}<.005)$, verbal assault $(\mathrm{p}<.001$, and direct assault $(\mathrm{p}<.05)$. The effect sizes ranged from medium $(\mathrm{r}=.26)$ to large $(\mathrm{r}=.43)$, with a large average effect size $(\mathrm{r}=.34)$. SPT alone was predictive of improvement in Barratt Factor 3 (non-planning impulsivity) $(\mathrm{p}<.02$, effect size $r=.31$ ). Thus, TFP predicted significant improvement in 10 of the 12 variables across the 6 domains, DBT in 5 of 12, and SPT in 6 of the 12 variables.

It is becoming clear from our study and that of others that BPD is a chronic but treatable disorder. What remains unclear, however, is how the treatments produce changes in the patient during the treatment that result in significant clinical improvement. Do the various treatments operate in the manner in which the authors hypothesize? For example, do patients in DBT reduce suicidal behavior because they learn affect regulation skills during the treatment and apply them when needed? In the randomized clinical trial noted above, we (Levy et al., 2006) utilize a measure of reflective functioning (RF) derived from the structured interview the AAI (George et al., 1998) to assess RF prior to and after one year of treatment with TFP, DBT, or SPT (Fonagy et al., 1998). We found, as hypothesized, that TFP significantly improved reflective functioning, whereas reflective functioning did not change in the other two treatments (Levy et al., 2006). There was a significant effect of treatment group on RF post-treatment after the effect of pre-treatment RF was controlled for $(\mathrm{p}<.05)$ with a very large overall effect size $(\mathrm{r}=.89)$. Patients in the TFP treatment condition significantly increased RF compared with DBT $(\mathrm{p}<.05$, medium effect size, $r=.27)$, and SPT $(\mathrm{p}<.05$; large effect size, $r=.39$ ). This suggests that TFP operates as hypothesized, namely, it leads to a significant improvement in the patients' capacity to reflect upon their thoughts, feelings, intentions of themselves and significant others in their lives (Levy et al., 2006; Yeomans et al., 2008).

\section{New learning in the application of TFP}

As our clinical experience broadened with a wider spectrum of borderline patients we found that certain practical variations in our technical approach were helpful for particular cases. There has been no overall change in our general technical approach, but rather a flexible adaptation to individual cases. Some typical examples include severely narcissistic patients whose dismissive and consistently 
arrogant behavior could be quite provocative of intense countertransference reactions, and where systematic analysis of the relation between a pathological grandiose self and the projected devalued, inferior part of self projected onto the therapist needed early and consistent attention. Generally provocative and challenging behavior of some borderline patients tended to move the therapist into a reinforced, chronic countertransference reaction showing as either inhibition in his interpretive efforts, or involvement in countertransference acting out: arguing with the patient, or premature pessimism regarding the treatment. Patients with antisocial behavior were mostly prone to premature disruption of the treatment.

Environmental conditions that were clearly harmful to the patient's life and even survival, such as severely abusive boyfriends or parental figures, required modification in the initial contract setting. Certain therapists were not able to maintain the appropriate speed - the tempo of intervention; other therapists were tempted to shift into supportive techniques when confronted with crises, which reinforced patients' acting out.

The interpretive clarification of patients' contradictory affect states was very difficult with some patients necessitating a much slower approach to these confrontations, so that the rhythm and duration of interpretive 'cycles' took more time than we had generally anticipated. We have not found the difficulties with symbolization hypothesized by Bateman and Fonagy: many patients showed such a difficulty at points of intense affective storms, but not in 'cooler' periods of the treatment.

While ours is a manualized treatment, it should be emphasized that this approach cannot be learned only from a book. On the contrary, ongoing supervision seemed to be the essence, and the mutual supervisory process of senior clinicians stimulated more junior ones to openly ask for help and be able to accept it.

\section{Indications and contraindications}

On the basis of our clinical experience achieved in the course of the development of our project, we arrived at the following recommendations regarding the practical applications of TFP.

The most general indication for Transferenced Focused Psychotherapy (TFP) is for patients with borderline personality organization, that is, presenting severe identity diffusion, severe breakdown in work and intimate relationships, in their social life, and with specific symptoms linked to their particular personality disorder. This indication includes most personality disorders functioning at a borderline level, such as the borderline personality disorder per se, the more severe cases of histrionic personality disorder, paranoid personality disorders, schizoid personality disorders, narcissistic personality disorders functioning on an overt borderline level (that is, having all the symptoms of borderline personality disorder and narcissistic personality disorder as well), and patients functioning at a borderline level with severe complications typical of these cases, if and when such complications can first be treated and controlled. These include alcoholism, drug dependency, severe eating disorders, particularly severe anorexia nervosa, patients with antisocial behavior but definitely not with an antisocial personality proper (which has no indication for psychotherapeutic treatment), schizotypal disorders, and severe hypochondriasis. In all individual cases, we evaluate first whether, even for such severe personality 
disorders, psychoanalysis may be the treatment of choice, as, for example, is the case for many histrionic personality disorders.

The main contraindications include, as mentioned before, the antisocial personality proper, and some narcissistic patients with severe antisocial features, as well as patients with chronic dishonesty that affects their capacity for verbal communication, such as pervasively dominant pseudologia fantastica: in short, severe degrees of chronic dishonesty that limit the capacity for honest communication and make the resolution of these psychopathic transferences very difficult. In contrast, patients with aggressive, provocative, irresponsible social behavior who, however, still are able to experience some degree of loyalty, investment in friendship and work, are optimal candidates for TFP.

Another major contraindication is overwhelming secondary gain of illness, provided by financial social support, supportive housing, financial means provided to many patients with severe personality disorders, who, unfortunately, are treated as if they were chronic schizophrenic patients, and whose capacity to lead a parasitic life depending on the State or on wealthy families becomes a major life-sustaining goal. Patients without any social life at all, reduced for many years to staying in their room, watching television, and drifting in some way through life, also have a reserved prognosis but in many cases can be treated if an adequate treatment contract is in place. Patients should optimally have a normal IQ in order to undergo TFP.

There are patients in whom an inordinate amount of self-directed aggression expresses self-destruction as a major life goal, and the wishes to destroy themselves may be more powerful than the wishes to live and be treated. Some of these patients can be recognized before the treatment starts, others only in the course of the treatment, although a long series of extremely severe suicidal attempts and a long history of what seems almost willful destruction of life opportunities may signal this condition. Many of the patients with contraindications for TFP psychotherapy may have an indication for supportive psychotherapy, a subject to which our Personality Disorders Institute has contributed significantly (Appelbaum, 2006; Rockland, 1992).

\section{The relationship between Transference Focused Psychotherapy and alternative psychoanalytic approaches}

The comparison of Transference Focus Psychotherapy (TFP) with an ego psychological approach to psychoanalysis has already been outlined in pointing to the use of the same analytic tools - interpretation, transference analysis, and technical neutrality - but with the modification of these techniques in TFP spelled out before, signaling the difference between TFP and psychoanalysis proper. Listening to an individual session of TFP and of psychoanalytic treatment, one might notice few differences between the two, but over a period of time the differences in employment of techniques would reveal a different atmosphere of treatment.

Important correspondences between TFP and ego psychological psychoanalysis are the consistent focus on the patient's immediate behavior in the hours, the proceeding from surface to depth, and starting from a common basis of observations shared by patient and therapist, that reflects the new developments in ego psychology related to defense analysis as spelled out by Gray (1996) and Busch (1992, 2000). It needs to be pointed out, however, that Kleinian analysis has also shifted, 
in recent years, to focus on the dominant anxieties in the 'here and now' rather than immediately pursuing the assumed deepest level of anxiety as proposed in traditional Kleinian technique (Spillius, 1988).

Regarding the differences between TFP and traditional ego psychologically based psychoanalytic psychotherapy as taught in American university settings over the past 50 years, TFP is more centered on transference interpretation, avoids supportive techniques in order to facilitate full development of the transference, and, because of the empirical research that has facilitated its gradual development, may be described as more specific and precise with regard to the use of parameters and techniques, leading to clearer delimitations from other approaches.

We have mentioned before that, to an ego psychologically trained psychoanalyst, some of the technical interventions in TFP, the frequency of interventions, the early nature of transference interpretation, may all convey a Kleinian aspect to TFP. Indeed, insofar as TFP leans heavily on the contributions of the Kleinian school regarding primitive defenses operations, object relations, and the nature of early condensation of oedipal and preoedipal conflicts, it fully utilizes the corresponding contributions from that school, particularly the work of Bion (1968, 1970), Rosenfeld (1964, 1971, 1978, 1987), Steiner (1987, 1993), and others (Spillius, 1988). In effect, comparing the facility and difficulties that psychoanalysts from different theoretical orientations show when undergoing training in TFP, our experience has been that psychoanalysts with a basic Kleinian orientation have the greatest facility for acquiring the technique of TFP and learning it with remarkable speed.

The main difference of TFP with standard Kleinian psychoanalysis, apart from the reduced session frequency of TFP, the face-to-face setting, and the therapist's ongoing 'scanning' of the patient's life outside the sessions, is the nature of the modification of technical neutrality in TFP in the sense of limit-setting under conditions of threat to the patient's physical well-being, to the patient's life, or under conditions of major threats to the patient's social survival stemming from his psychopathology. As mentioned before, technical neutrality oscillates throughout the treatment, and the therapist's bringing into the analytic situation major life problems of the patient that appear to present urgency while not emerging, at that time, as dominant themes in the transference is in contrast to the Kleinian analyst's efforts to be guided almost exclusively by the transference in formulating interpretative comments.

Insofar as the intersubjective/relational approach to psychoanalysis tends to put less emphasis on aggressive features and on primitive sexuality, similarly to the selfpsychological approach, TFP also would differ from that approach. However, the strong focus on the immediate interactional processes that characterizes the intersubjective/relational approach is similar to the ongoing focus on the immediate interpersonal interactions in TFP, as is also the ongoing focus on countertransference developments. One important difference, however, is that direct countertransference communication, recommended by some authors of the relational approach (Renick, 1993, 1996) stands in sharp contrast to Transference Focused Psychotherapy's systematic non-communication of countertransference, as already mentioned. And TFP attempts to explore profound levels of primitive fantasies and object relations that diverge gradually from the more surface levels of interaction in focusing on the patient's intrapsychic life. 
Mentalization based therapy (MBT) is a new psychoanalytic psychotherapy for borderline conditions proposed by Bateman and Fonagy (2004a, 2004b) that also has been confirmed as empirically effective in the treatment of these conditions in a day hospital setting (Bateman and Fonagy, 1999, 2001), and is based on a consistent effort to increase the patient's mentalization, namely, the patient's capacity to recognize mental states in himself and in others, and to acquire, in the process, a capacity for self-reflection and appropriate assessment of others in depth that would significantly improve his mental functioning and general symptomatology. Although this assumption is formulated somewhat differently from our efforts to resolve identity diffusion, it refers to the related processes of developing the patient's realistic and integrated sense of self that would permit him to evaluate any particular affective state from the perspective of that integrated self, and to evaluate the mental states of others within the context of a realistic assessment of others in depth.

The important difference lies in MBT's assumption that early interpretation is dangerous and potentially damaging because it imposes a formulation on the patient that does not correspond to his experienced mental state. We disagree with this assumption and believe that it is based on confusing (a) the nature of interpretation with healthier patients, where defensive operations center on repression and interpretation points to unconscious meanings that were not in the patient's conscious mind but that, through free association, may become conscious as a response to correct interpretations, with (b) the different nature of interpretation indicated when the predominant defensive operations are primitive dissociation or splitting and not repression. In this latter case, interpretation is not directed to 'impose' mental contents on the patient that he does not experience conscientiously, but is geared to help the patient link different mental states that he is dissociatively, but conscientiously experiencing in the context of his interactions with the therapist.

However, insofar as, with the exception of the greater emphasis on the treatment contract and parameters of treatment in TFP, the initial phases of TFP and the description of MBT are practically identical, we suggest that MBT corresponds closely to the initial phase of TFP, and the fact that this in itself is already helpful to patients reinforces our general view that contemporary psychoanalytic psychotherapy for severe personality disorders that is cognizant of the nature of the psychic structure and the corresponding transference developments of these patients is an important and helpful modality of treatment.

\section{Differences with SP, DBT, and SFT}

Comparison of TFP with other empirically supported treatments for borderline personality - MBT (Bateman and Fonagy, 1999), supportive psychotherapy (SP) (Clarkin et al., 2007), dialectic behavioral therapy (DBT) (Linehan, 1993; Linehan et al., 2006) and schema focused therapy (SFT) (Giesen-Bloo et al., 2006; Young et al., 2003) - introduces the question of how treatments based on somewhat different understandings of the pathology and how to treat it have all been shown to be correlated with improvement in symptoms. This may be explained to some degree by the role of elements of therapy that are not specific to a particular model. Or, as Gabbard suggests, it may be that there are specific effects of different techniques of therapy and that we are nearing a time when therapeutic approaches can be chosen according to the specific 'clinical constellation' of the individual patient (Gabbard, 
2007). A fuller discussion of proposed 'mechanisms of action' in the models of therapy considered here can be found elsewhere (Clarkin and Levy, 2006).

A general difference between TFP and ST, DBT, SFT, and also MBT is that the latter ones see BPD as a disorder based on deficit rather than on internal conflict. To compare TFP more specifically with psychodynamic supportive psychotherapy (SP), starting from the same theoretical basis, SP attempts to strengthen directly patients' adaptive functioning by means of cognitive support (advice-giving, information-giving), affective support (reassurance, praise, verbal conveyance of empathy), direct intervention in the patient's life outside the sessions, and non-interpretation of the transference in consonance with a non-technically neutral attitude. In SP, efforts to foster and protect a positive transference are the method preferred to facilitate identification with the therapist's emotional and cognitive attitude and views of the relevant emotional conflicts. TFP, in contrast, is based on a consistent attitude of technical neutrality, non-utilization of supportive techniques, and systematic transference analysis in the 'here and now'.

Regarding the cognitive-behavioral-based integrative approaches, DBT and SFT, TFP differs in attempting to resolve intrapsychic conflicts between contradictory internalized object relations and the distortions of perception that accompany them, with a strong emphasis on integrating projected internalized object relations. In contrast, DBT sees borderline pathology as based primarily on an individual's emotional dysregulation and combines validation of affective states with teaching skills to tolerate distress, to avoid or distract in order to reduce or eliminate painful emotions, and to stop problem behaviors. These techniques have been associated with symptom reduction (Linehan et al., 2006). Along with the differences, there are interesting similarities between TFP and DBT in terms of the need for a clear and articulated treatment structure, a sense of the priority of issues to be addressed, a continuing stress on and protection of the frame of the treatment, and the need for ongoing supervision groups.

Within schema focused therapy (SFT), the concept of maladaptive schemas (ways of experiencing self and others) may bear a similarity to the concept of object relations dyads. However, the two concepts differ in that schemas are seen as cognitions that, while not in the patient's awareness, have not been modified by the psychological forces (drives, fantasies, etc.) described in psychoanalytic writings and are not kept from awareness by dynamic forces. Based on a deficit model of BPD, SFT sees inadequate parenting as leaving the patient with unfulfilled 'core childhood needs', such as safety, a stable base, predictability, love, nurturing, attention, acceptance, praise, empathy, realistic limits, and the validation of feelings and needs. The therapy is meant to provide the patient with fulfillment of these needs with strategies including: cognitive restructuring, emotion-focused techniques, behavioral life pattern change, 'limited reparenting', and 'schema mode work'. SFP is explicitly supportive, recommending, among other things, that the therapist nurture, praise, provide extra time and transitional objects, and, 'when appropriate', physically hold the patient. This model, like DBT and to some extent like MBT, rejects the need to integrate aggressive affects, seeing all aggressive affects as stemming from justifiable anger.

In conclusion, Transference Focused Psychotherapy, a psychoanalytic treatment modality specifically geared to treat severe personality disorders, is a significant extension of psychoanalytic treatment for a broad spectrum of patients, empirically 
validated to an extent that warrants further exploration of its role in the treatment of a large, severely ill and challenging patient population.

\section{Translations of summary}

Übertragungsfokussierte Psychotherapie: Überblick und Update. Dieser Beitrag beschreibt eine psychoanalytische Psychotherapie, die speziell für Patienten mit schweren Persönlichkeitsstörungen entwickelt wurde; er erläutert das technische Verfahren sowie spezifische Forschungsprojekte, die die Effektivität der Methode empirisch nachgewiesen haben. Diese Behandlung beruht auf den Erkenntnissen des Menninger Foundation Psychotherapy Project und benutzt ein Modell der modernen psychoanalytischen Objektbeziehungstheorie als theoretische Grundlage. Der Beitrag unterscheidet diese Behandlung nicht nur von alternativen psychoanalytischen Verfahren einschließlich anderer Methoden der psychoanalytischen Psychotherapie sowie der Standard-Psychoanalyse, sondern auch von drei alternativen, nicht-analytischen Behandlungen, die in der Behandlung von Borderline-Patienten führend sind, nämlich die dialektische Verhaltenstherapie, die supportive, auf der psychoanalytischen Theorie beruhende Psychotherapie und die schema-fokussierte Therapie. Der Beitrag schließt mit Indikationen und Kontraindikationen dieses spezifischen therapeutischen Verfahrens. Ihnen liegt die klinische Erfahrung zugrunde, die im Laufe einer Serie von Forschungsprojekten gesammelt werden konnte, die den empirischen Nachweis seiner Effektivität erbrachten.

Psicoterapia enfocada en la transferencia: panorama y actualización. Este trabajo describe una psicoterapia psicoanalítica específica para pacientes con severos desórdenes de personalidad, su enfoque técnico y proyectos de investigación específicos que establecen evidencias empíricas que apoyan su eficacia. Este tratamiento se deriva de los hallazgos del proyecto de investigación de psicoterapia de la Fundación Menninger, y aplica como fundamento teórico un modelo de la teoría psicoanalítica contemporánea de las relaciones objetales. El artículo hace una diferencia entre este tratamiento de enfoques psicoanalíticos alternativos -incluidos otros tipos de psicoterapia psicoanalítica como también el psicoanálisis estándar- y tres tratamientos no-analíticos alternativos prevalecientes en el tratamiento de pacientes fronterizos o borderline: la terapia dialéctico-conductual, la psicoterapia de apoyo basada en la teoría psicoanalítica, y la terapia enfocada en los esquemas. Concluye con indicaciones y contraindicaciones a este enfoque terapéutico particular, derivadas de la experiencia clínica que evolucionó en el curso de la secuencia de los proyectos de investigación que condujeron al establecimiento empírico de su eficacia.

La psychothérapie centrée sur le transfert : vue d'ensemble et mise à jour. Cet article décrit une psychothérapie psychanalytique spécifique pour des patients présentant des troubles sévères da la personnalité, son approche technique et des projets de recherche spécifiques destinés à établir des preuves empiriques de son efficacité. Ce traitement s'inspire des découvertes du projet de Recherche en Psychothérapie de la Fondation Menninger et applique un modèle de la théorie psychanalytique contemporaine des relations d'objet, qui est son fondement théorique. L'article différencie ce traitement des approches psychanalytiques alternatives (aussi bien les autres types de psychothérapie psychanalytique que la psychanalyse classique), ainsi que de trois types de traitements non analytiques utilisés de façon prévalente dans le traitement des patients états-limite, à savoir : la thérapie comportementale dialectique, la psychothérapie de soutien reposant sur la théorie psychanalytique et la thérapie centrée sur les schémas. L'article conclut sur les indications et les contre-indications de cette approche thérapeutique particulière qui est issue de l'expérience clinique et qui a évolué dans le cours du déroulement des projets de recherche, conduisant à l'établissement empirique de son efficacité.

Psicoterapia centrata sul transfert: rassegna e aggiornamento. Questo articolo descrive un tipo specifico di psicoterapia psicoanalitica per pazienti con gravi disturbi della personalità, il suo approccio tecnico e l'efficacia del quale è stata accertata da progetti di ricerca volti a stabilire un'evidenza empirica. Questo trattamento deriva dalle scoperte del progetto Menninger Foundation Psychotherapy Research e applica un modello della teoria psicoanalitica di relazioni oggettuali come base teorica. Il lavoro distingue questo tipo di trattamento da altri metodi di psicoterapia psicoanalitici, dalla psicoanalisi tradizionale, e da tre tipi di psicoterapia non-psicoanalitica prevalenti nel trattamento di pazienti borderline: la terapia comportamentale dialettica, la terapia di sostegno fondata sulla teoria psicoanalitica e il modello cognitivo Schema-focused Therapy. In conclusione vengono definite le indicazioni e le controindicazioni per questo particolare metodo psicoterapeutico risultante dall'esperienza clinica emersa nel corso della sequenza di progetti di ricerca che hanno consentito di stabilirne l'efficacia.

\section{References}

Appelbaum AH (2006). Supportive psychoanalytic psychotherapy for borderline patients: An empirical approach. Am J Psychoanal 66(4):317-32.

Bateman A, Fonagy P (1999). The effectiveness of partial hospitalization in the treatment of borderline personality disorder: A randomized control trial. Am J Psychiatry 156:1563-9. 
Bateman A, Fonagy P (2001). Treatment of borderline personality disorder with psychoanalytically-oriented partial hospitalization: An 18 month follow-up. Am J Psychiatry 158:36-42.

Bateman A, Fonagy P (2004a). Psychotherapy for borderline personality disorder: Mentalization-based treatment. New York, NY: Oxford UP.

Bateman A, Fonagy P (2004b). Mentalization-based treatment of BPD. J Pers Disord 18(1):36-51.

Bion WR (1968). Second thoughts: Selected papers on psychoanalysis. New York, NY: Basic Books.

Bion WR (1970). Attention and interpretation. London: Heinemann.

Busch F (1992). Recurring thoughts on unconscious ego resistances. J Am Psychoanal Assoc 40:1089-115.

Busch F (2000). What is deep interpretation? J Am Psychoanal Assoc 48:237-54.

Clarkin JF, Foelsch PA, Levy KN, Hull JW, Delaney JC, Kernberg OF (2001). The development of a psychodynamic treatment for patients with borderline personality disorder: A preliminary study of behavioral change. J Pers Disord 15:487-95.

Clarkin JF, Levy KN, Lenzenweger MF, Kernberg OF (2004). The Personality Disorders Institute/Borderline Personality Disorder Research Foundation randomized control trial for borderline personality disorder: Rationale, methods, and patient characteristics. J Pers Disord 18:52-72.

Clarkin JF, Levy KN editors (2006). Putative mechanisms of action in the psychotherapy treatment of borderline personality disorder. J Clin Psychol 62:481-501.

Clarkin JF, Yeomans FE, Kernberg OF (2006). Psychotherapy for borderline personality: Focusing on object relations. Washington, DC: American Psychiatric.

Clarkin JF, Levy KN, Lenzenweger MF, Kernberg OF (2007). Evaluating three treatments for borderline personality disorder: A multiwave study. Am J Psychiatry 164:922-8.

Fenichel O (1941). Problems of psychoanalytic technique. Albany, NY: Psychoanalytic Quarterly.

Fonagy P, Steele M, Steele H, Target M (1998). Reflective functioning manual: Version 5. For application to Adult Attachment Interviews. London: University College.

Gabbard G (2007). Do all roads lead to Rome? Findings on borderline personality disorder (editorial) $A m \mathrm{~J}$ Psychiatry 164:853-5.

George C, Kaplan N, Main M (1998). The Berkeley Adult Attachment interview. Unpublished manuscript, Berkeley, CA: Department of Psychology, University of California.

Giesen-Bloo J, Van Dyck R, Spinhoven P, Van Tilburg W, Dirksen C, Van Asselt, et al. (2006). Outpatient psychotherapy for borderline personality disorder: A randomized clinical trial of schema focused therapy versus transference focused psychotherapy. Arch Gen Psychiatry 63:649-58.

Gill M (1954). Psychoanalysis and exploratory psychotherapy. J Am Psychoanal Assoc 2:771-97.

Gray P (1996). Undoing the lag in the technique of conflict and defense analysis. Psychoanal Stud Child 51:87-101.

Green A (1993). On private madness. Madison, CT: International UP.

Green A (2000). La position phobique centrale. In: La Pensée clinique. Paris: Odile Jacob. [(2000). The central phobic position: A new formulation of the free association method. Int J Psychoanal 81:429-51.]

Kazdin AE (2004). Psychotherapy for children and adolescents. In: Lambert MJ, editor. Bergin and Garfield's handbook of psychotherapy and behavior change. 543-89. 5th edn. New York, NY: Wiley.

Kernberg O (1984). Severe personality disorders: Psychotherapeutic strategies. New Haven, CT: Yale UP.

Kernberg O (2004). Aggressivity, narcissism, and self-destructiveness in the psychotherapeutic relationship: New developments in the psychopathology and psychotherapy of severe personality disorders. New Haven, CT: Yale UP.

Kernberg O (2006). Identity: Recent findings and clinical implications. Psychoanal Q 75:969-1004.

Kernberg O, Burnstein ED, Coyne L, Appelbaum A, Horwith L, Voth H (1972). Psychotherapy and psychoanalysis: Final report of the Menninger Foundation's psychotherapy research project. Bull Menninger Clin 36:1-275.

Lenzenweger MF, Clarkin JF, Kernberg OF, Foelsch PA (2001). The Inventory of Personality Organization: Psychometric properties, factorial composition, and criterion relations with affect, aggressive dyscontrol, psychosis proneness, and self-domains in a nonclinical sample. Psychol Assessment 13: 577-91.

Lenzenweger MF, Clarkin JF, Fertuck EA, Kernberg OF (2004). Executive neurocognitive functioning and neurobehavioral systems indicators in borderline personality disorder: A preliminary study. J Pers Disord 18:421-38.

Levy KN (2006). Re: New publication in the archives on a comparison of Schema (Young) Focus. Message to psychodynamic research, archived at psychodynamicresarch@yahoogroups.com [11 June 2006].

Levy KN, Meehan KB, Kelly KM, Reynoso JS, Weber M, Clarkin JF, Kernberg OF (2006). Change in attachment patterns and reflective function in a randomized control trial of transferenced-focused psychotherapy for borderline personality disorder. J Consult Clin Psychol 74:1027-40.

Linehan MM (1993). Cognitive-behavioral treatment of borderline personality disorder. New York, NY: Guilford.

Linehan MM, Comtois KA, Murray AM, Brown MZ, Gallop RJ, Heard HL, Korslund KE, Tutek DA, Reynolds SK, Lindenboim N (2006). Two-year randomized controlled trial and follow-up of dialectical behavior therapy versus therapy by experts for suicidal behavior and borderline personality disorder. Arch Gen Psychiatry 63:757-66. 
Posner MI, Rothbert MK, Vizueta N, Thomas KM, Levy KN, Fossella J, Silbersweig D, Stern E, Clarkin J, Kernberg OF (2003). An approach to the psychobiology of personality disorders. Dev Psychopathol 15:1093-106.

Renick O (1993). Analytic interaction: Conceptualizing technique in light of the analyst's irreducible subjectivity. Psychoanal Q 65:553-71.

Renick O (1996). The perils of neutrality. Psychoanal Q 65:495-517.

Rockland LH (1992). Supportive therapy for borderline patients: A psychodynamic approach. New York, NY: Guilford.

Rosenfeld H (1964). On the psychopathology of narcissism: A clinical approach. Int J Psychoanal 45:332-7.

Rosenfeld H (1971). A clinical approach to the psychoanalytic theory of the life and death instincts: An investigation into the aggressive aspects of narcissism. Int $J$ Psychoanal 52:169-78.

Rosenfeld H (1978). Notes on the psychopathology and psychoanalytic treatment of some borderline patients. Int J Psychoanal 59:215-21.

Rosenfeld H (1987). Impasse and interpretation: Therapeutic and anti-therapeutic factors in the psychoanalytic treatment of psychotic, borderline, and neurotic patients. London: Tavistock.

Sandler J, Sandler AM (1987). The past unconscious, the present unconscious, and the vicissitudes of guilt. Int $J$ Psychoanal 8:331-41.

Silbersweig D, Clarkin JF, Goldstein M, Kernberg OF, Tuescher O, Levy K, Brendel G, Pan H, Beutel M, Pavony T, Epstein J, Lenzenweger MF, Thomas K, Posner MI (2007). Failure of fronto-limbic inhibitory function in the context of negative emotion in borderline personality disorder. Am J Psychiatry 164:1832-41.

Spillius EB, editor (1988). Melanie Klein today: Developments in theory and practice. London: Routledge.

Steiner J (1987). The interplay between pathological organizations and the paranoid-schizoid position. Int $J$ Psychoanal 68:69-80. [Also in: Spillius EB, editor. Melanie Klein today vol. I, Mainly theory, 324-42. London: Routledge, 1988.]

Steiner J (1993). Psychic retreats: Pathological organization in pychotic, neurotic and borderline patients. London: Routledge.

Yeomans FE, Selzer MA, Clarkin JF (1992). Treating the borderline patient: A contract-based approach. New York, NY: Basic Books.

Yeomans FE (2007). Questions concerning the randomized trial of schema-focused therapy vs transferencefocused psychotherapy. Letter to the Editor. Arch Gen Psychiatry 64(5):609-10.

Yeomans FE, Clarkin JF, Diamond D, Levy KN (2008). An object relations treatment of borderline patients with reflective functioning as a mechanism of change. In: Busch FN, editor. Mentalization: Theoretical considerations, research findings, and clinical implications, 159-81. Hillsdale, NJ: Analytic Press.

Young JE, Klosko J, Weishaar ME (2003). Schema therapy: A practitioner's guide. New York, NY: Guilford. 